\title{
Project \#CyborgArt: A Teaching Case Study on the Affordances Programmable Sensors in Mixed Media Art Projects
}

\author{
Susan Sweeney \\ Lecturer \\ School of Arts, \\ Dublin Business School, Dublin, Ireland \\ Stephen Howell \\ Academic Engagement Manager, \\ Microsoft Academic Team, Dublin, Ireland
}

(C) Sweeney \& Howell. This work is licensed under the Creative Commons AttributionNonCommercial-ShareAlike 4.0 International License. To view a copy of this license, visit https://creativecommons.org/licenses/by-nc-sa/4.0/.

\section{Abstract}

Modern graduates of all disciplines require proficiency with new literacies to complement and enhance traditional higher-level education. Local and multinational businesses struggle to source graduates with both practical skills, an understanding of the modern consumer, and the challenges of integrating technology safely into almost every facet of life. This paper presents a multi-disciplinary module project that required students to create a mixed-media art piece representing the students' vision of themselves as cybernetic organisms. The module was delivered over one semester and incorporated industry speakers and workshops on non-traditional topics for the discipline of these students. One of these topics was Coding for Non-Coders and Wearable and Embeddable Technology. This paper examines the affordances the students gained by learning how to incorporate simple, cheap but effective sensors in their art.

Keywords: Graduate Skills, Modern Consumer, Human, Technological, \& Data Literacies, Computational Thinking, Wearables, Sensors

\section{Introduction}

This paper presents a teaching case study on a single semester module delivered to approximately 30 college students from varied courses including Film \& Media Studies and Journalism. The module combined learning outcomes and presented practical 
skills across modules such as Multimedia Tools, Portfolio Production, and Life-Long Learning. The module required significant effort on the students' part, including an assignment where they needed to create a mixed-media art pieces, visits to galleries and workshops from external industry guest speakers.

The theme for this class project deliverable was Cyborg Art. The assignment became known as \#CyborgArt and is referred to as such throughout this paper.

\section{Cyborgs}

Building on the concept that modern humans rely on technology in largely invisible ways, this module introduced cyborgs to the students as an example of a combined technological and biological organism. This aimed to equip students with the conceptual ideas of safely integrating technology while improving their practical skills with the ability to produce artefacts, reflect and present them in a portfolio.

In Simians, cyborgs, and women (Haraway, 1991) identifies a cyborg as a cybernetic organism; a hybrid of machine and organism. Media commentators (Case, 2015) have suggested that most humans have become cyborgs by increasing engagement with mobile devices and that these devices have become modern mankind's new tools for living. Consumers are increasingly embracing technology to manage their physical needs, such as training with a fitness tracker. The global fitness tracker business in 2017 included 35 million 'Smart wristband' unit shipments worldwide and Fitness tracker device revenue worldwide in 2017 was $\$ 2.51$ bn (Statista, 2017).

\section{New Digital Literacies}

Graduates must be equipped with a new set of competencies and literacies to meet the needs of this type of consumer. Post Human Condition (Pepperell, 2003) proposes the term post human to refer to the general convergence of technology and biology to the point where they are increasingly becoming indistinguishable. They argue that the distinction between machines and humans is becoming less clear at the same time as it becomes increasingly hard to imagine how modern society would survive without technological aids.

Industry research groups that identify emerging and growing trends (PwC Global, 2017 ) report that the essential technologies that businesses are embracing include:

1) Artificial Intelligence (AI),

2) Augmented Reality (AR),

3) Blockchain,

4) Drones,

5) Internet of Things,

6) Robotics, 
7) Virtual Reality (VR) and

8) 3-D Printing.

Businesses that seek to develop and engage with emerging technologies create a competitive business advantage. Whilst the job-destroying applications of Al are what command the headlines (e.g. driverless cars), today computers are much better at managing other computers and digital information than they are at managing human interactions (Ramaswamy, 2017).

Education theorists agree that the high priority in education is to help individuals acquire the information, the personal growth and the learning that will enable them to deal more constructively with the real world (Rogers, 1980). In Robot-Proof (Aoun, 2017), the assertion that graduates need to build on traditional literacies by adding three new literacies, technological literacy, human literacy, and data literacy is explored. These new literacies will help students rise above the processing power of computers by engendering creativity.

The characteristics of each of these literacies:

a) human literacy which includes the student's communication skills, knowledge of the humanities, design skills and the ability to function in the human milieu;

b) technological literacy which gives students a grounding in engineering and coding so that they know how machines intrinsically operate and

c) data literacy so that they can read and analyse the rising tide of information.

\section{Learning Objectives}

The learning objectives and outcomes of the \#CyborgArt project are mapped directly to human, technological, and data literacy. Students were tasked with creating an image of themselves modified to incorporate technological and data components so that they could demonstrate understanding of the new literacies. Class activities included visiting the National Gallery of Ireland and participating in-class discussion about post-humanism concepts. Technological and data literacy elements were explored using a range of software and hardware which was to be incorporated into student projects. Students' visual interactions and understanding of gestalt design principles also enhance visual literacy skills which are important for many areas of business (e.g. UX, data visualisation).

Students produced an e-portfolio capturing and reflecting on project outputs. The online blog element to the project also enhances the student profile since it facilitates reflection, enhances metacognition, and provides content for the student's digital portfolio. The sum of the skills acquired during the project are transferable to the work 
place and can be adopted as part of any employability module e.g. in Arts, Science, Engineering, or Business Studies.

Four main objectives to the teaching project were identified:

1) To equip learners with a practical understanding of fundamental design principles, multimedia, web tools and coding concepts, device uses and file types via a range of authoring tools, techniques, and platforms.

2) To develop the practical skills and an understanding of the planning and publishing skills needed to implement a multimedia project and ePortfolio web publishing digital artefact and gallery exhibition of physical artefact artwork.

3) To provide learners with a knowledge of artificial intelligence, human literacy including visual literacy, problem solving, metacognition and technological literacy including coding and data literacies.

4) To produce a project roadmap that can be adapted across programmes in a range of higher education institutions.

\section{Learning Outcomes and Amplification of learning}

Having engaged with the project students would be able to demonstrate:

1) Human literacy skills: Engage with design, communication, collaboration, metacognition, problem solving skills. Explain the fundamental concepts of design principles. Develop intrinsic motivation factors.

2) Technological Literacy: Develop coding language techniques, engage with hardware set-up and manipulation, engage with digital image manipulation, and with file types.

3) Data Literacy: Develop the ability to read images and engage with abstract thinking. This ability plays a big part in the conceptualizing and pattern matching used in data and big data analyses. The use of data visualisation in business requires an understanding of visual literacy and pattern recognition.

4) Develop a meaningful visual scape with interactive technology. Demonstrate an understanding of event planning. Exhibition of work.

\section{Pedagogical Approach}

The lecturer adopted a constructivist/social constructivist approach to learning using technology as a tool (Papert, 1990; Gagne, Briggs and Wager, 1992; Sweeney and Hughes, 2017). The teaching and learning experience focused on creative and problem-solving activities for students which are scaffolded and supported by the lecturer. Through these activities, the learner was encouraged towards autonomy. Lecturer interactions that included positive reinforcement lead to a learning result where student gratification can be observed (Sweeney, 2009). 


\section{Project \#CyborgArt in the Classroom}

The project involved the production of virtual and physical artefacts by students. Students were invited to express their artistic flair by digitally manipulating their own profile image and creating a futuristic version of themselves by incorporating the notion of their future selves as cyborg learners.

In order to promote and reinforce gestalt design principles, art history and the notion of aesthetic; students were brought on a field trip to the National Gallery of Ireland and were invited to observe, reflect and discuss the paintings on display. Students further researched the notion of 'cyborgs' and 'post humanism' and the results of such research was discussed in class which led to Cartesian philosophical debate and metaphysical exploration. Students also discussed various cyborg themed films including, I Robot (2004), and Al (2001). The humanoid Sophia was also introduced and discussed in class.

Students then created digital artefacts of their profile images as a cybernetic being. Each cyborg artefact included an individual unique QR code thus allowing the viewer to digitally scan the physical artefact and view the student's digital portfolio. This provided an interesting physical/virtual feedback loop. The final artefacts were embellished with physical objects including metal pieces and lights. Each piece was exhibited as a collective installation in a constructed gallery space. 
Figure 1: Sophia the humanoid on stage with her creators at Hanson Robotics' Web Summit 2017 (McCarthy, 2017).

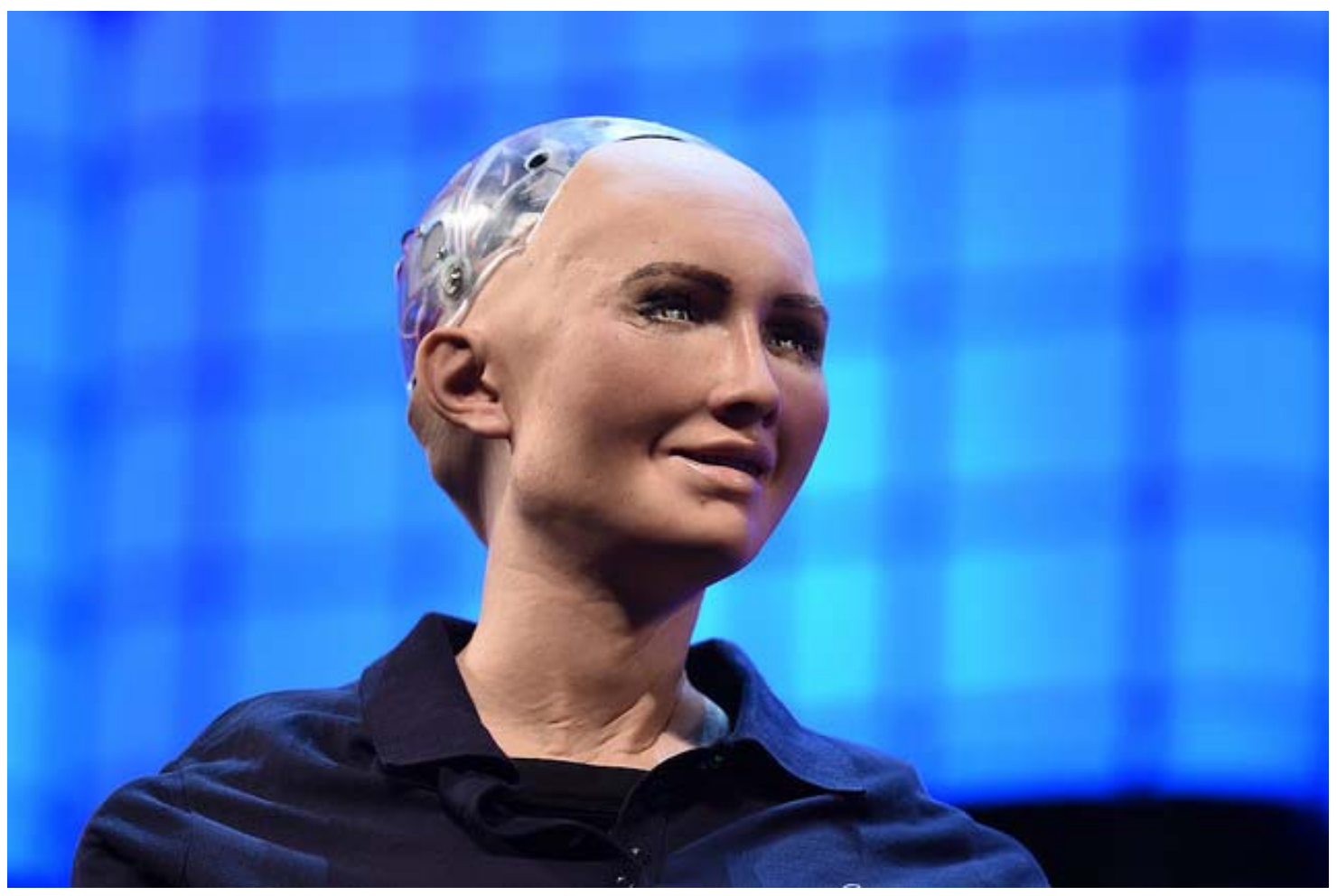

\section{Assessment}

Students were presented with a potential roadmap to project completion which was not prescriptive, so students could incorporate more advanced art or technical skills in their submissions if they had the skills to do so. The range of software used included photography and compositing software, presentation software and web publishing software. Students were presented with a range of tools but were free to use any tools they had expertise in. This constructivist teaching approach providing roadmap (but not a prescriptive set of instructions) allowed some students to explore aspects of the assignment that they found interesting at greater depth than their peers.

The suggested roadmap outline that students could follow:

1. Take or source a personal headshot photograph, ensure the file format is appropriate for image manipulation

2. Digitally manipulate the headshot to create a digitally enhanced photograph of their profile, incorporate cybernetic imagery

3. Engage with the lecturer to ensure the manipulated photograph is appropriate, fits the target aesthetic, and incorporate their feedback and critique 
4. Using a web publishing platform, write a descriptive and reflective blog post on the experience and engagement with the project. Incorporate the blog into a digital e-portfolio

5. Add a unique QR code to the final image so viewers can access the student's e-portfolio

6. Prepare a physical art canvas including the image, optionally embellishing the canvas with physical objects

\section{Incorporating Sensors to the Mixed-Medium Art}

The lecturer expanded upon the roadmap above by inviting industry collaborators to present workshops to the students. One workshop was run by the Microsoft Ireland Academic Team. They presented a small micro-processor device called a micro:bit, which was invented to teach students Computational Thinking. The micro:bit is a small (half-credit card sized) microprocessor with an LED screen display and a Bluetooth Low Energy radio (Ball et al., 2016).

Because the students generally had no coding experience prior to the workshop, coding the micro:bit was taught using a Visual Programming Language. The programming environment used was Microsoft MakeCode (Ball, 2017), a free and opensource integrated development environment. Though other programming languages (such as typed syntax languages) can be used to program the micro:bit, they have a significant learning curve and are beyond the scope of a short workshop.

The affordances available using the micro:bit include the ability to sense light, temperature, motion and force.

The artefacts were then enhanced with micro:bit sensors. This final step allowed each cyborg art piece to communicate with one another to become part of a collaborative borg. For instance, a micro:bit could detect if a bright light was shone upon a single piece and all the other art pieces could react.

The additional roadmap steps were added as follows:

7. Follow the 4 Ds of Software Development: Design, Develop, Debug, and Deploy

i. $\quad$ Design the capabilities required for the sensors and micro:bit

ii. Develop a micro:bit program using MakeCode to achieve the design

iii. Debug (remove errors) until the code is correct and functional

iv. Deploy the code to the micro:bit

8. Attach the micro:bit to the canvas art work and test collectively with the other art

9. Exhibit the work as part of a collective exhibition.

10. Update the reflective blog/portfolio. 


\section{Student Feedback}

As this was a pilot project to examine the potential for non-STEM major students to learn and demonstrate new literacies, students were pre or post-surveyed, and neither quantitative nor qualitative analysis was performed. For the next iteration of this project, the researchers intend to survey and quantify the student attitudes, capabilities, and attainment resulting from completing this module.

However, the lecturer did elicit open feedback on the module, and the relevant feedback is included below:

- "The \#CyborgArt project was truly inspiring. To consider humanity as a cyborg made me delve into my own psyche, discovering the cogs and wheels that make up who I am as a creative individual. In the curation of the image I learned not only a new skill in photo manipulation but also a different kind of reflective thought. I was ignorant to the use of $\mathrm{Al}$ in the wider world and as a result of the Cyborg project I now see its presence throughout my daily life. The influence of the project is incredible as I now work with a company that specialises in Al and data science recruitment."

- "In creating my Cyborg for \#CyborgArt I drew on the idea that even as adults the desire to learn still remains. Inside of my cyborg are the cogs of a machine, a machine that is made of old parts but is adapting and evolving to new ideas. The Cyborg is the future."

- "When my lecturer first mentioned the idea of cyborg project, immediately Arnold Schwarzenegger and the terminator came to mind. I wanted to create something similar and I thought it would be interesting to link the "bad and good" concept into the image as well. Therefore I used half of my face to represent my evil side trapped in the cyborg world and the other side as sweet and innocent, the real me. I used the other picture of the matrix as a background behind the 'cyborg me' which also refers to the pulling power of the other world, the dark side."

- "My final digital image, represents how I am learning through technology while I am studying abroad and my Celtic tattoo represents my time here in Ireland. The technology has been helpful and also harmful while I have been here. Often times it is easy to live through technology and not enjoy the present. Me as a cyborg is developing and embracing changes, while also using technology to reflect on what is going on in my life in the most present form."

- "For my 'Cyborg' I decided to take inspiration from the work of Pablo Picasso, with a focus on his representation of women in portraits. For the background of my portrait I sampled pieces from Picasso portraits and embedded them within my own image. We used PowerPoint to edit the image and created a QR code to embed into the image that would link to our digital portfolio." 
Figure 2. Student cyborg art and (inset) Microsoft MakeCode

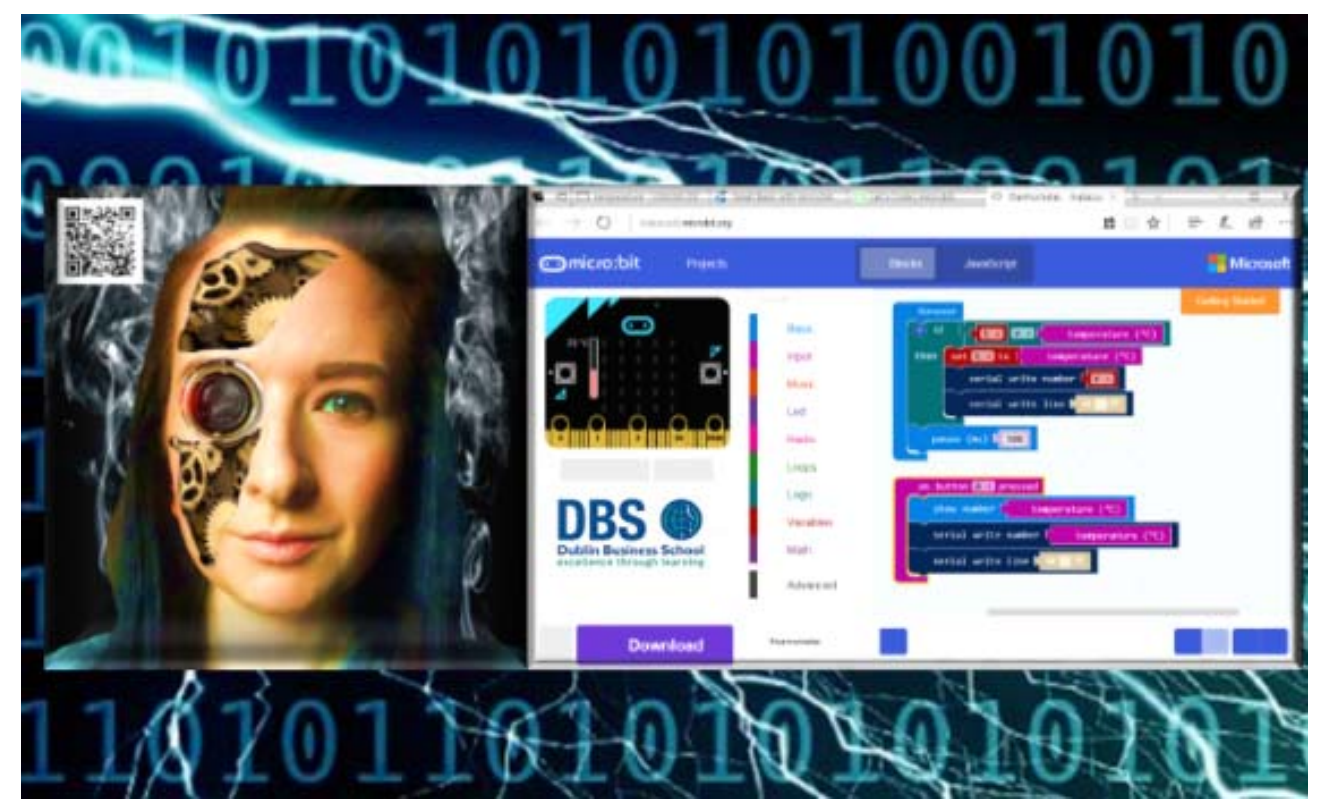

Figure 3: Student ePortfolio.
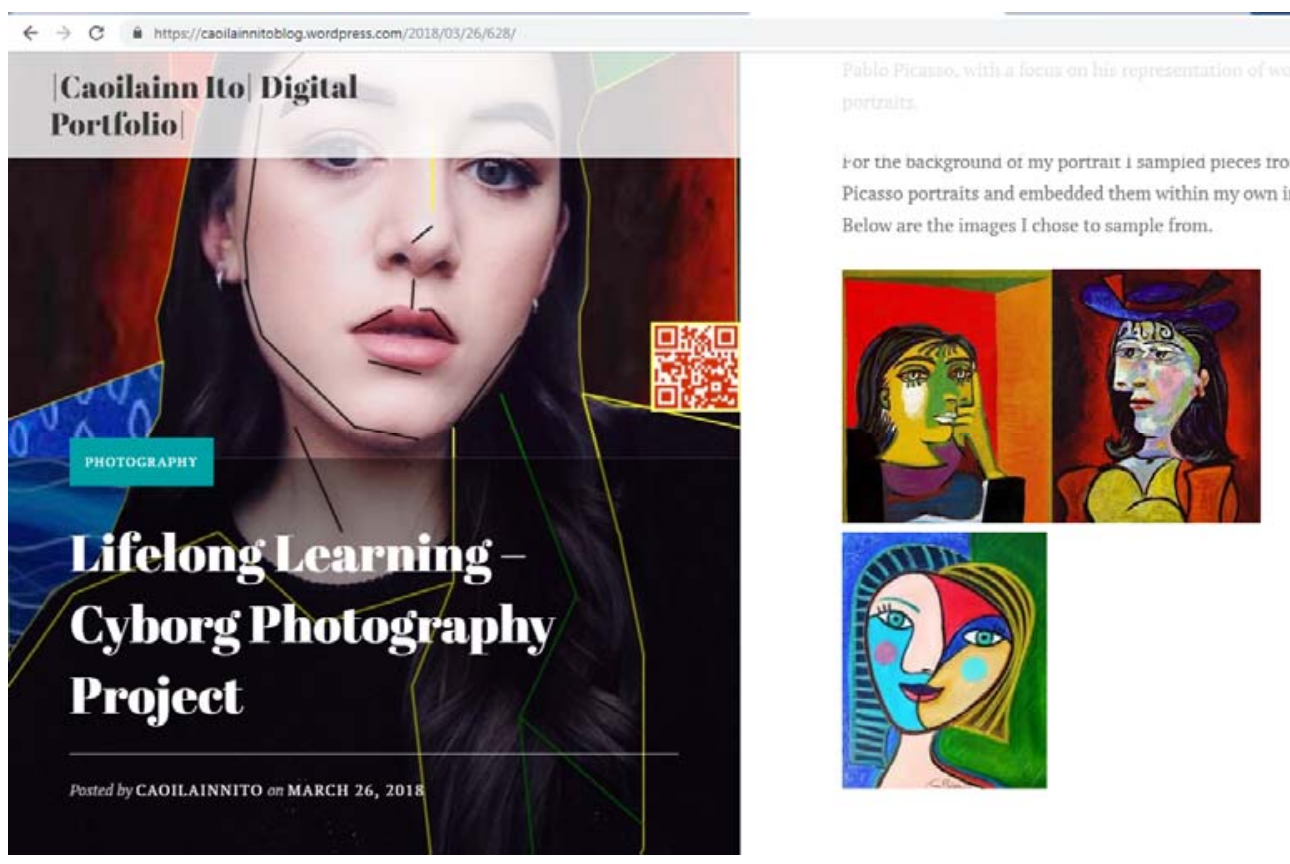
Figure 4: Printed canvas artefacts with exposed micro:bits.

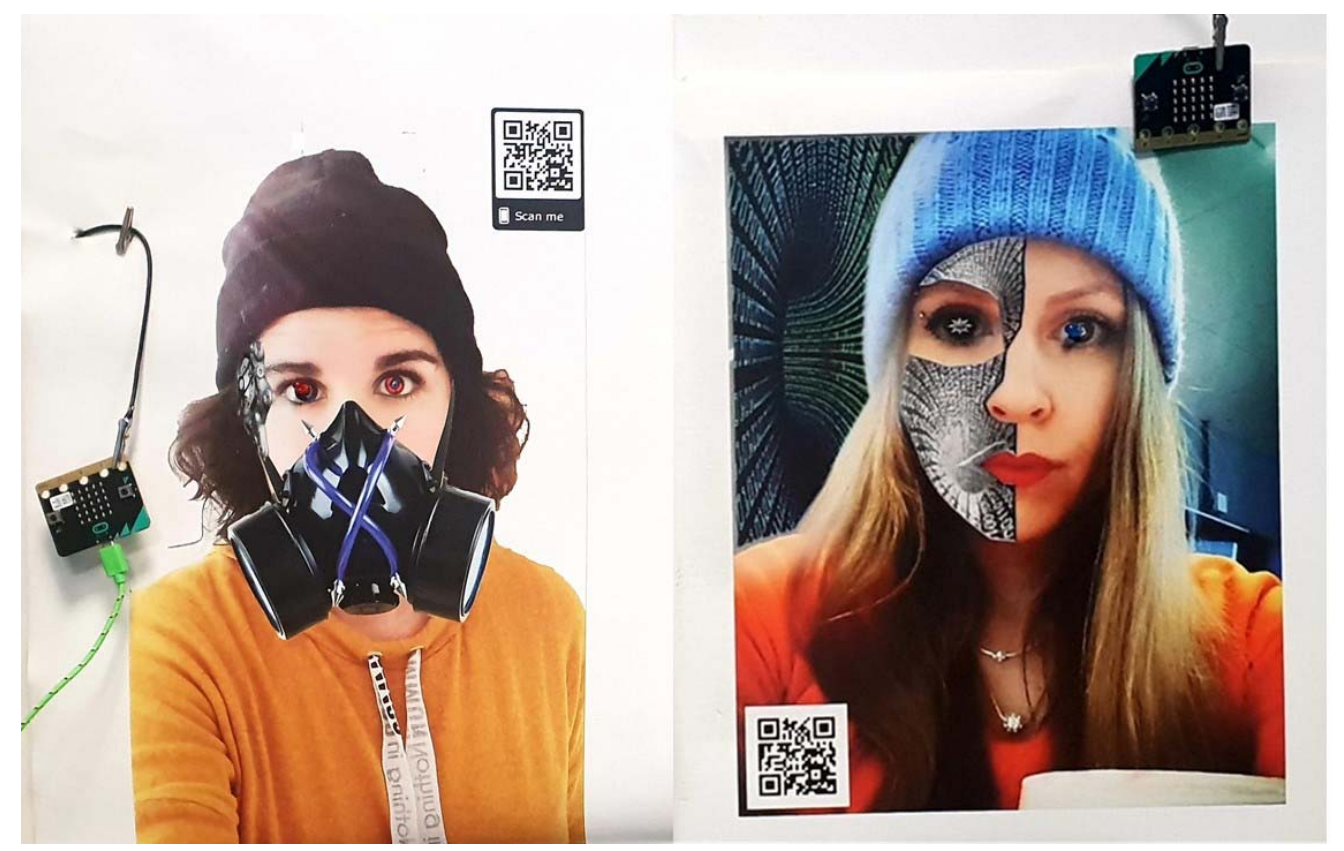

\section{Conclusion}

The \#CyborgArt Project adopted a constructivist approach to learning. High student engagement was particularly noticeable when the students embellished their artefacts with physical and digital objects. Creative engagement with this technology in the higher education environment is pivotal in order to produce graduates that can compete with machines and that can also meet the needs of the cyborg consumer. By manipulating an image of themselves to incorporate technological and data components, students gained direct insight into the human and learner as cyborg acquiring new literacies in the process. The insights and skills gained in this project equips the graduate with the skills to meet the needs of the cyborg as a hybrid consumer and provider.

\section{References}

Aoun, J. (2017) Robot-proof: higher education in the age of artificial intelligence. Cambridge, MA: The MIT Press.

Ball, T. (2017) 'Physical computing for everyone', in Software Engineering Education and Training Track. IEEE/ACM 39th International Conference on Software Engineering, Buenos 
Aires: IEEE, p. 3. Available at:

https://ieeexplore.ieee.org/stamp/stamp.jsp?tp=\&arnumber=7964323\&isnumber=7964313 (Accessed: 15 November 2018).

Ball, T., Protzenko, J., Bishop, J., Moskal, M., de Halleu, J., Braun, M., Hodges, S. and Riley, S. (2016) 'Microsoft touch develop and the bbc micro:bit', in. IEEE/ACM 38th IEEE International Conference on Software Engineering Companion, Austin, Texas: IEEE, pp. 637-640. Available at:

https://ieeexplore.ieee.org/stamp/stamp.jsp?tp=\&arnumber=7883359\&isnumber=7883261\&t $\underline{\mathrm{ag}=1}$ (Accessed: 15 November 2018).

Case, A. (2015) Are our devices turning us Into a new kind of human?, NPR. Available at: https://www.npr.org/2015/09/11/438944317/are-our-devices-turning-us-into-a-new-kind-ofhuman (Accessed: 15 November 2018).

Gagné, R. M., Briggs, L. J. and Wager, W. W. (1992) Principles of instructional design. 4th ed. Fort Worth: Harcourt Brace Jovanovich College Publishers.

Haraway, D. J. (1991) Simians, cyborgs, and women: the reinvention of nature. New York: Routledge.

McCarthy, S. (2017) [Flickr] 7 November. Available at: https://www.flickr.com/photos/websummit/38240096521 (Accessed: 15 November 2018).

Papert, S. (1990) A critique of technocentrism in thinking about the school of the future, Future of Learning Group MIT Media Laboratory. Available at: http://learning.media.mit.edu/publications papert.html (Accessed: 15 November 2018).

Pepperell, R. (2003) The posthuman condition: consciousness beyond the brain. New ed. Bristol, UK: Intellect.

PwC Global (2017) The essential eight: Your guide to the emerging technologies revolutionizing business now, PwC. Available at:

https://www.pwc.com/gx/en/issues/technology/essential-eight-technologies.html (Accessed: 22 October 2018).

Ramaswamy, S. (2017) 'How companies are already using Al', Harvard Business Review, pp. 2-6 Available at:

http://search.ebscohost.com/login.aspx?direct=true\&AuthType=ip, shib,cookie, url\&db=bth\&A

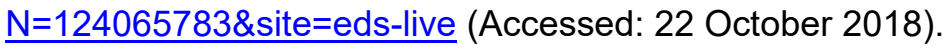

Rogers, C. R. (1980) A way of being. Boston: Houghton Mifflin.

Statista (2017) Statistics \& facts on wearable technology, www.statista.com. Available at: https://www.statista.com/topics/1556/wearable-technology/ (Accessed: 15 November 2018). 
Sweeney, S. (2009) Abstract - Colouring in the violin: A graphically-mediated approach to the reconstruction of heard melodies, Irish Learning Technology Association. Available at: http://ilta.ie/abstract-colouring-in-the-violin-a-graphically-mediated-approach-to-thereconstruction-of-heard-melodies/ (Accessed: 30 October 2018).

Sweeney, S. and Hughes, D. (2017) 'Integrating visual literacy training into the business curriculum. A case study at Dublin Business School', DBS Business Review, 1, pp. 61-97. 